\title{
Modifying Carbon Supports of Catalyst for the Oxygen Reduction Reaction in Vehicle PEMFCs
}

\author{
Qiong Xue ${ }^{1} \cdot$ Daijun Yang ${ }^{1}$ (D) Lei Jiang $^{1} \cdot$ Bing Li $^{1} \cdot$ Pingwen Ming ${ }^{1}$
}

Received: 14 September 2020 / Accepted: 2 April 2021 / Published online: 1 May 2021

(c) The Author(s) 2021

\begin{abstract}
For current carbon-supported Pt catalysts in vehicle proton exchange membrane fuel cells (PEMFCs), the insufficient stability and durability of carbon supports are severe limitations under operating conditions. This paper adopts the accelerated stress test (AST) method to study the carbon corrosion of catalysts, which is significant to efficiently select the catalysts supports in fuel cells. Graphitized carbon blacks with various surface properties are heated under different conditions, followed by evaluation of their antioxidation capacity with the AST. It is shown that optimally graphitized carbon blacks demonstrate superior stability, retaining a constant quinone/hydroquinone $(\mathrm{QH})$ transition peak potential for over 70,000 AST cycles. A Pt catalyst supported on the selected graphitized carbon exhibits excellent durability at both the rotating disk electrode (RDE) and membrane electrode assembly (MEA) levels. The final specific mass activity (MA) of the optimum catalyst is $47.87 \mathrm{~mA} /$ $\mathrm{mg}_{\mathrm{Pt}}$, which is 2.06 times that of commercial Pt/C $\left(23.31 \mathrm{~mA} / \mathrm{mg}_{\mathrm{Pt}}\right)$ in the RDE tests. The final maximum power density of the optimum catalyst is $525.68 \mathrm{~mW} / \mathrm{cm}^{2}$, which is $305.52 \mathrm{~mW} / \mathrm{cm}^{2}$ higher than that of commercial Pt/C after undergoing the AST during the MEA measurements. These results prove that the rational surface features of carbon supports play a vital role in improving the overall fuel cell performance by realizing uniform dispersion of Pt nanoparticles, resisting corrosion, and reinforcing metal-support interactions.
\end{abstract}

Keywords Proton exchange membrane fuel cells · Graphitized carbon black · Oxygen reduction reaction · Durability

$\begin{array}{ll}\text { Abbreviations } \\ \text { AST } & \text { Accelerated stress test } \\ \text { CV } & \text { Cyclic voltammetry } \\ \text { ECSA } & \text { Electrochemically active surface area } \\ \text { FCV } & \text { Fuel cell vehicle } \\ \text { LSV } & \text { Linear sweep voltammetry } \\ \text { MEA } & \text { Membrane electrode assembly } \\ \text { ORR } & \text { Oxygen reduction reaction } \\ \text { PEMFC } & \text { Proton exchange membrane fuel cell } \\ \text { RDE } & \text { Rotating disk electrode }\end{array}$

Daijun Yang

yangdaijun@tongji.edu.cn

1 Clean Energy Automotive Engineering Center \& School of Automotive Studies, Tongji University, 4800 Caoan Road, Shanghai 201804, China

\section{Introduction}

Proton exchange membrane fuel cells (PEMFCs) have become attractive options for deep decarbonization of vehicle powertrain systems due to their unique characteristics, such as short refueling times, long ranges, low operating temperatures, and use of nonpolluting energy $[1,2]$. However, PEMFCs suffer from high cost and insufficient durability, which restricts the large-scale commercial application of fuel cell vehicles (FCVs) [3]. The US Department of Energy set a 2025 durability target of $8,000 \mathrm{~h}$ (equivalent to 150,000 miles of driving) with less than $10 \%$ of performance loss, to compete with automotive internal combustion engines [4]. The current durability status is significantly below the 2025 target, which is caused by catalyst deactivation [5]. The sluggish oxygen reduction reaction (ORR) kinetics in the cathode influences the overall PEMFC performance [6, 7]. Recently, both platinum group metal (PGM) catalysts and PGM-free catalysts for the ORR have been studied to improve the performance and reduce the cost $[6,8]$. Emerging atomically dispersed transition metals and nitrogen-codoped 
carbon (M-N-C) catalysts have been explored to lower the cost of PEMFCs, but still exhibit lower-than-expected performance in terms of their activity, stability, durability, and membrane electrode assembly (MEA) performance [9]. In the past decade, the best atomically dispersed $\mathrm{M}-\mathrm{N}-\mathrm{C}$ catalysts have just reached catalytic comparable activity to that of $\mathrm{Pt} / \mathrm{C}$ catalysts in liquid acids based on rotating disk electrode (RDE) measurements [6]. Nevertheless, the current knowledge of and methods for transferring the catalytic properties of $\mathrm{M}-\mathrm{N}-\mathrm{C}$ catalysts from the RDE to MEA performance are still limited $[9,10]$.

Currently, Pt or Pt-based materials are still the most commonly used catalysts that exhibit state-of-the-art performance for the ORR $[11,12]$. The catalyst support plays a vital role in deciding the overall MEA performance because it participates in the construction of a three-phase boundary for charge and mass transport. Carbon blacks, as the widely used support materials for fuel cell catalysts, include XC-72 and Ketjen black, etc., which are adopted due to their high conductivity, low cost, and great performance [12, 13]. However, the corrosion of carbon black supports at high potential significantly degrades the catalyst performance via migration and agglomeration, along with detachment of surface-loaded Pt nanoparticles [14, 15]. In real-world vehicle operating conditions, carbon corrosion is most commonly caused by the formation of a hydrogen-air interface in the start-up/shutdown stage. Under actual FCV operating conditions, the carbon supports always suffer thermodynamic corrosion since the theoretical oxidation potential of carbon black is $0.207 \mathrm{~V}$ (vs. the reversible hydrogen electrode, RHE) [16]. Carbon substrate corrosion will significantly decrease the electrochemically active surface area (ECSA) of $\mathrm{Pt}$ and increase the number of oxygen-containing groups on the carbon surface [17]. The forming of oxygen functional groups can lead to partial oxidation of Pt particles, causing facile dissolution and Ostwald ripening of $\mathrm{Pt}$ nanoparticles, and weakening the Pt-support interaction, which triggers detachment and agglomeration of Pt nanoparticles [15, 18, 19]. The results from Kim et al. [18] indicated that electrons in Pt nanoparticles near oxygen functional groups could be withdrawn by highly electronegative oxygen, resulting in oxidation and Oswald ripening. In addition, the collapse of the support pore structure and loss of hydrophobic properties occur due to severe carbon corrosion, thereby deteriorating the mass transfer in the cathode catalyst layer [20, $21]$. As carbon with a low degree of graphitization is prone to corrosion [6], ideal carbon supports should have sufficient long-range ordered graphitic structures. In addition, the ideal carbon support should be equipped with favorable surface properties to reinforce metal-support interactions and disperse nanoparticles uniformly. Only by achieving the best balance between the graphitization degree and surface properties of carbon supports can the overall performance of MEAs be enhanced.

The direct indicator of the stability of carbon support is its weight loss or $\mathrm{CO} / \mathrm{CO}_{2}$ emissions during cycling [22]. Cremers et al. [23] used a combination of differential electrochemical mass spectrometry and online mass spectrometry during single-cell testing to study carbon support corrosion. The mass loss of carbon could be monitored to evaluate the carbon corrosion of electrocatalysts in fuel cells. Although this method provides insights into the carbon support-related degradation of fuel cell catalysts, it needs to be performed at the single-cell level to evaluate the corrosivity of various carbon supports, which would require more experiments for the synthesis and testing of catalysts. The intensity or area ratio of the $D$ to $G$ peaks in the Raman spectrum is usually used to represent the degradation degree of carbon materials $[24,25]$. However, it cannot be obtained during accelerated tests for in situ characterization. E. N. Gribov et al. [26] proposed a corrosion model for porous carbon materials to qualitatively and quantitatively evaluate the sample resistance of carbon supports from cyclic voltammogram evolution. The shift in the quinone/hydroquinone $(\mathrm{QH})$ transition peak could be used as an indicator of the decisive role of the degradation degree in the overall resistance.

Therefore, enhancing the antioxidation capacity of carbon supports and rapidly evaluating their electrochemical stability can effectively speed up the development of highly durable catalysts for FCVs. This paper investigates the anticorrosion property of various graphitized carbon blacks via an accelerated stress test (AST) method to select the catalysts supports for automotive PEMFCs. Notably, this AST method has been used to study the carbon corrosion of typical carbon blacks in regard to their selection as supports for catalysts in fuel cells. The durability of the corresponding Pt catalysts supported on carbon blacks for the ORR at both the RDE and MEA levels agrees with the above antioxidation results of the carbon blacks. This agreement confirms the reliability of the AST method for carbon support selection in fuel cells. This paper provides a method for the efficient selection of carbon supports for the ORR in vehicle PEMFCs, which would save experimental effort and time spent on the synthesis and testing of catalysts.

\section{Experiments and Methods}

\subsection{Graphitization of Carbon Black}

BP (BP2000, Cabot), EC300 (Ketjen black), and EC600J (Ketjen black) carbon blacks are selected as main objects 
and pre-treated under different conditions. In detail, the carbon blacks are mixed with nickel nitrate hexahydrate $\left(\mathrm{Ni}\left(\mathrm{NO}_{3}\right) \cdot 6 \mathrm{H}_{2} \mathrm{O}, \mathrm{AR}\right.$, Sinopharm Chemical Reagent Co., Ltd.) at a mass ratio of $4 / 1$ in ethanol (AR, Sinopharm Chemical Reagent Co., Ltd.) to obtain mixtures, and then the mixtures are sonicated and dried to make them uniform. After that, the mixtures are treated with a rate of $20^{\circ} / \mathrm{min}$ and kept for $3 \mathrm{~h}$ at $1300{ }^{\circ} \mathrm{C}, 1600{ }^{\circ} \mathrm{C}, 1900{ }^{\circ} \mathrm{C}, 2200{ }^{\circ} \mathrm{C}$, and $2500{ }^{\circ} \mathrm{C}$, respectively, at the atmosphere of Ar gas in a graphite furnace (GJC-SML-100, Zhuzhou Guangjichang Technology Co., Ltd.). Then, the prepared graphitized carbon powder is treated with diluted hydrochloric acid $(\mathrm{HCl}$, AR, 37 wt.\%, Sinopharm Chemical Reagent Co., Ltd.) at a constant temperature of $80{ }^{\circ} \mathrm{C}$ for $2 \mathrm{~h}$ to remove $\mathrm{Ni}$ ions. After filtering the acid solution, the remaining filter cake is washed and filtered with an abundance of ultrapure water $\left(18.25 \mathrm{M} \Omega \cdot \mathrm{cm} @ 25{ }^{\circ} \mathrm{C}\right)$. Then, the washed filter cake is dried in a vacuum oven (DZF-6020, Shanghai Jinghong Equipment Co., Ltd.) at $80{ }^{\circ} \mathrm{C}$ for $24 \mathrm{~h}$ to obtain a clean graphitized powder.

Vulcan XC-72 is used as a reference in the performance characterization of the obtained carbon black materials.

\subsection{Catalyst Synthesis}

Catalysts are synthesized by the formic acid reduction method. The specific steps are as follows: First, the prepared graphitized carbon black powder and chloroplatinic acid hexahydrate $\left(\mathrm{H}_{2} \mathrm{PtCl}_{6} \cdot 6 \mathrm{H}_{2} \mathrm{O}\right.$, AR, Sinopharm Chemical Reagent Co., Ltd.) are separately dispersed and dissolved in ethylene glycol (AR, Sinopharm Chemical Reagent Co., Ltd.), followed by mixing the above dispersed liquids and a certain amount of formic acid that is added dropwise with rapid stirring in a $\mathrm{N}_{2}$ atmosphere. Second, a certain amount of sodium carbonate solution is added to the above mixed liquid at $80^{\circ} \mathrm{C}$, and the mixture is refluxed for $3 \mathrm{~h}$. After the mixed reaction liquid cools to room temperature naturally, its $\mathrm{pH}$ is adjusted to 4 using a preconfigured $0.5 \mathrm{~mol} / \mathrm{L}$ $\mathrm{HCl}$ ethylene glycol solution, and it is allowed to precipitate overnight. Finally, the sediment is washed and filtered using excess ultrapure water after removing the supernatant. The obtained filter cake is dried in a vacuum oven at $80{ }^{\circ} \mathrm{C}$ for $12 \mathrm{~h}$.

\subsection{MEA Fabrication}

An MEA with a $25 \mathrm{~cm}^{2}$ area is constructed by the spraying method. The anode is a commercial $40 \mathrm{wt} \% \mathrm{Pt} / \mathrm{C}$ (Johnson Matthey) catalyst, and the cathode is the homemade catalyst. The counterpart of the cathode is commercial 40 wt $\% \mathrm{Pt} / \mathrm{C}$. The Pt contents are 0.4 and $0.2 \mathrm{mg} / \mathrm{cm}^{2}$ for the anode and cathode, respectively. In detail, certain amounts of catalyst powder, ultrapure water, isopropanol (AR, Sinopharm Chemical Reagent Co., Ltd.), and Nafion ${ }^{\circledR}$ solution (where $\mathrm{m}(\mathrm{Pt} / \mathrm{C}): \mathrm{m}\left(\right.$ Nafion $\left.{ }^{\circledR}\right)=3: 1$ ) are ultrasonically mixed to form a uniform ink. This Nafion content could balance the trade-off between proton conduction and mass transfer. It is sufficient to form an effective proton transport network while not occupying the pore channel. The temperature of the sprayer console (Exacta Coat, Sonotek) is set to $80^{\circ} \mathrm{C}$, and the anode ink and cathode ink are evenly sprayed on both sides of a Nafion ${ }^{\circledR} 212$ proton exchange membrane to form a catalyst-coated membrane module (CCM). The CCM and carbon paper (28BC, SGL) are packed to obtain fuel cell membrane electrodes.

\subsection{Characterization of Microstructure}

Scanning electron microscopy (SEM) is adopted on the Quanta 250 FEG instrument (FEI), to observe the surface morphology of the catalysts. Transmission electron microscopy (TEM) is performed with a JEM-2010HT instrument (JEOL). X-ray diffraction (XRD) is performed with a D8 Advance instrument (Bruker AXS). Raman spectroscopy is carried out with a LabRAM HR Evolution instrument (HORIBA J.Y.) that utilizes an argon laser (514 nm). Inductively coupled plasma mass spectrometry (ICP-MS) is conducted with a NexION300 instrument (PerkinElmer) to examine and calculate the loaded Pt content of the obtained catalysts. Specific surface area and pore analyses are performed with an ASAP2020 instrument (Micrometrics) with high-purity $\mathrm{N}_{2}$. The specific surface area of carbon support is calculated by the Brunauer-Emmett-Teller (BET) formula, and the pore size distribution of the sample is analyzed by the Barrett-Joyner-Halenda (BJH) method.

\subsection{Electrochemical Evaluation}

The RDE tests adopt a common three-electrode system, in which the RDE is coated with a carbon black or catalyst as the working electrode, a platinum wire electrode acts as the counter electrode, and a reversible hydrogen electrode (RHE) is the reference electrode. All RDE experiments are conducted in a $\mathrm{N}_{2}$-saturated $\mathrm{HClO}_{4}$ electrolyte. A quantitative sample (carbon black or Pt/C catalyst), ultrapure water, isopropanol, and Nafion ${ }^{\circledR}$ solution are mixed and sonicated to obtain an ink-like slurry with the sample being evenly dispersed in the solvent. Ten microliters of ink are used to evenly cover an RDE with an area of $0.196 \mathrm{~cm}^{2}$ to prepare a working electrode.

The electrochemical performance of the carbon blacks is characterized by cyclic voltammetry (CV) within a scanning potential range of $0-1.2 \mathrm{~V}$ (vs. RHE) at a $50 \mathrm{mV} / \mathrm{s} \mathrm{scan}$ rate. The anticorrosion properties of the carbon black supports 
are evaluated by an accelerated stress test (AST) within a scanning potential range of $1.0-1.5 \mathrm{~V}$ at a $500 \mathrm{mV} / \mathrm{s}$ scan rate [26].

The performance of the prepared catalysts is characterized by $\mathrm{CV}$ and linear sweep voltammetry (LSV). The scanning potential range for $\mathrm{CV}$ is $0.05-1.15 \mathrm{~V}$ (vs. RHE), and the scan rate is $50 \mathrm{mV} / \mathrm{s}$. The electrochemical surface area (ECSA) of each catalyst could be calculated based on the charge of the $\mathrm{H}$ desorption peak in the $\mathrm{CV}$ curve $[27,28]$. The equation is as follows:

$E C S A=Q_{H} /\left(0.21 * m_{P t}\right)$

where $Q_{\mathrm{H}}(\mathrm{mC})$ is the integral charge of the $\mathrm{H}$ desorption peak; the constant $0.21\left(\mathrm{mC} / \mathrm{cm}^{2}\right)$ is the charge of $\mathrm{H}$ atom monolayer desorption from a pure Pt surface; $m_{\mathrm{Pt}}$ is the mass load of Pt on the electrode.

The durability of the catalyst is evaluated by AST within a potential scanning range of $0.6-1.1 \mathrm{~V}$ at a $100 \mathrm{mV} / \mathrm{s} \mathrm{scan}$ rate [29]. The scanning potential range of the LSV test is $0.05-1.15 \mathrm{~V}$ (vs. RHE), using a scan rate of $5 \mathrm{mV} / \mathrm{s}$ at $1600 \mathrm{rpm}$. The specific mass activity (MA) of each catalyst is computed by the Koutecky-Levich formula [30]. The specific equation is as follows:

$1 / i=1 / i_{k}+1 / i_{d}$

where $i_{\mathrm{k}}$ represents the kinetic current and $i_{\mathrm{d}}$ is the diffusionlimiting current.

The MEA test is carried out on a G20 single-cell test platform (Greenlight Innovation) with a $\mathrm{H}_{2}$ /air (anode/ cathode) stoichiometric ratio of $1.7 / 3$, a relative humidity of $80 \% / 80 \%$, a cell temperature of $80{ }^{\circ} \mathrm{C}$, and a backpressure of $120 \mathrm{kPa}$. The performance is assessed by polarization curve, electrochemical impedance spectroscopy (EIS), and CV results. Galvanostatic EIS is performed on an electrochemical workstation (Reference 3000, Gamry) in a frequency range of $10 \mathrm{kHz}-0.1 \mathrm{~Hz}$. CV is conducted on the workstation with a scanning speed of $20 \mathrm{mV} / \mathrm{s}$ in a potential range of $0.05-1.15 \mathrm{~V}$ using $\mathrm{H}_{2} / \mathrm{N}_{2}$ (anode/ cathode) and $100 \% / 100 \%$ relative humidity to obtain the ECSA of the cathode catalyst in an MEA. The AST adopts the same method as that for the carbon black supports, that is, a scanning potential range of $1.0-1.5 \mathrm{~V}$ at a scan rate of $500 \mathrm{mV} / \mathrm{s}$.

\section{Results and Discussion}

\subsection{Characterization of the Prepared Carbon Blacks}

Figure 1a, $b$ shows the XRD spectra of the carbon black supports before and after the high-temperature graphitization (a)

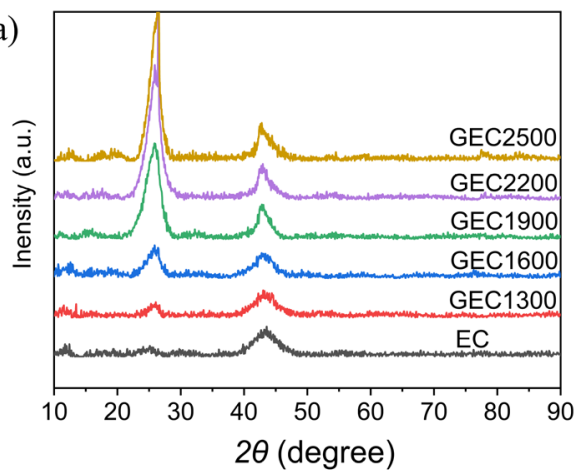

(b)

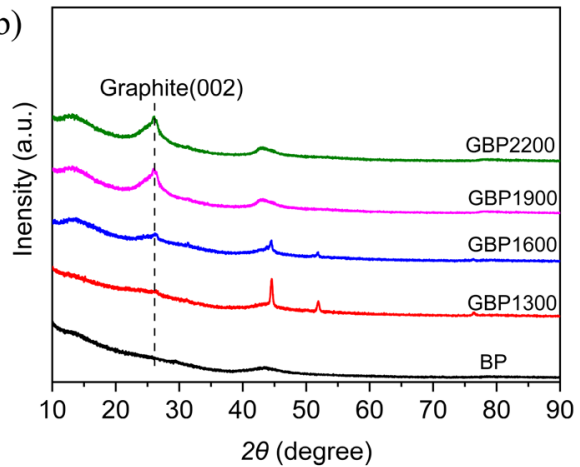

(c)

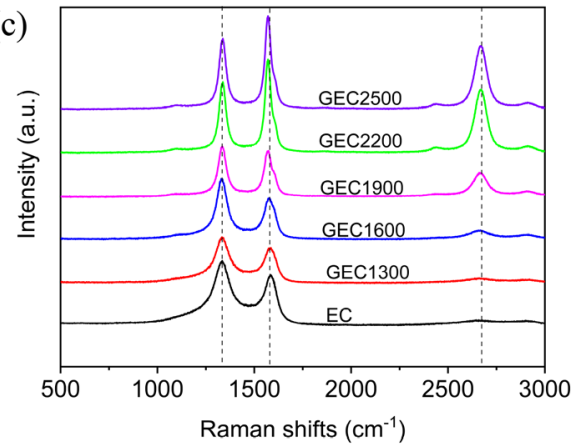

(d)

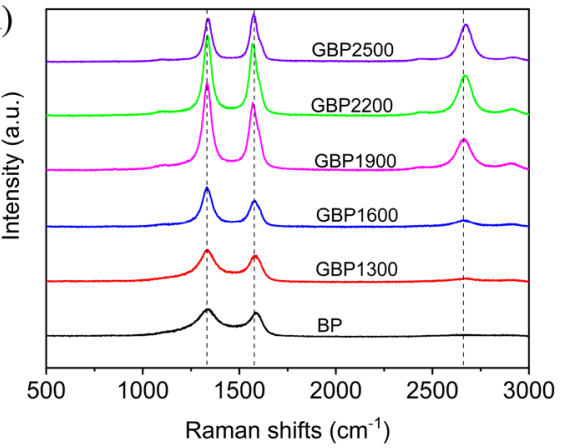

Fig. 1 XRD and Raman patterns of the prepared carbon blacks: a XRD patterns of the EC and GECs; $\mathbf{b}$ XRD patterns of the BP and GBPs; $\mathbf{c}$ Raman spectra of the EC and GECs; and d Raman spectra of the BP and GBPs

treatment. Compared with the original carbon blacks (BP and EC), both graphitized BP (GBP, except for GBP1300) and graphitization EC (GEC) exhibit a peak at a diffraction 
Table 1 Parameters of the prepared carbon blacks

\begin{tabular}{llc}
\hline Carbon blacks & Parameter \\
\cline { 2 - 3 } & $\mathrm{R}\left(I_{\mathrm{D}} / I_{\mathrm{G}}\right)$ & $\begin{array}{c}\text { BET specific sur- } \\
\text { face area }\left(\mathrm{m}^{2} / \mathrm{g}\right)\end{array}$ \\
\hline EC & 1.37 & 1386 \\
GEC1300 & 1.25 & 979 \\
GEC1600 & 1.17 & 660 \\
GEC1900 & 1.02 & 615 \\
GEC2200 & 0.94 & 225 \\
GEC2500 & 0.84 & 195 \\
BP & 1.35 & 1522 \\
GBP1300 & 1.25 & 622 \\
GBP1600 & 1.15 & 564 \\
GBP1900 & 1.09 & 314 \\
GBP2200 & 1.04 & 273 \\
GBP2500 & 0.95 & 185 \\
\hline
\end{tabular}

angle of $2 \theta=26.5^{\circ}$, corresponding to the hexagonal graphitic C (002) crystal plane, which signifies that defect sites or groups of amorphous carbon are eliminated and have transformed into an orderly layered graphite structure. As the treatment temperature increases, the graphite (002) peak becomes stronger, indicating a higher degree of graphitization. In addition, the diamond (111) crystal plane peak at $2 \theta=43^{\circ}$ (JCPDS NO.41-1487) in Fig. 1a does not disappear and shows little change after heat treatment, indicating that the structure is stable and is not influenced by hightemperature treatment.

To further measure the graphitization degree of the prepared carbon blacks, Raman spectroscopy is performed. As shown in Fig. 1c, d, all the spectra contain two main characteristic absorption peaks: the D peak at $1350 \mathrm{~cm}^{-1}$ and the $\mathrm{G}$ peak at $1580 \mathrm{~cm}^{-1}$. The 2D peak at $2680 \mathrm{~cm}^{-1}$ appears in some of the spectra. The $\mathrm{D}$ peak is caused by the irregular or low-symmetry structure of carbon, which is related to lattice defects and the symmetry of the long-range order that originates from double resonance Raman scattering [31]. The $\mathrm{G}$ peak results from the vibration of the conjugated $\mathrm{C}=\mathrm{C}$ in the hexagonal structure of graphite that originates from first-order Raman scattering [32]. The structure corresponding to the $2 \mathrm{D}$ peak is a complete graphite sheet structure or a highly ordered graphite lattice. The $I_{\mathrm{D}} / I_{\mathrm{G}}$ ratio of peak D to peak $\mathrm{G}$ is usually used to measure the structural defect degree of a sample. The larger the value is, the more surface defects there are, and thus, the lower the order is. Therefore, this ratio can be used to judge the functionalization degree of the covalently modified surface and graphitization [33].

The calculated $R$ value is exhibited in Table 1. These results show that the $\mathrm{R}$ value has a negative correlation with the graphitization temperature, indicating that the disordered carbon structure continuously dissolves during the (a)

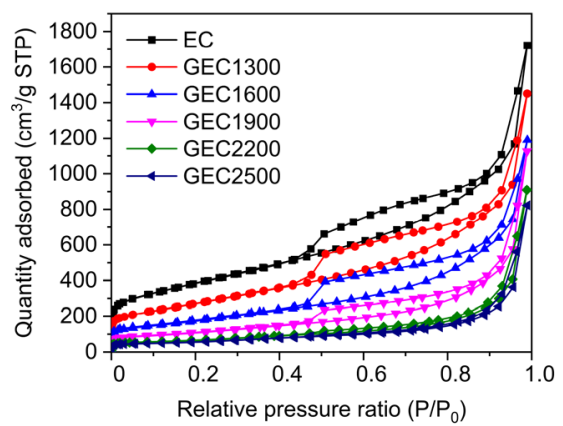

(b)

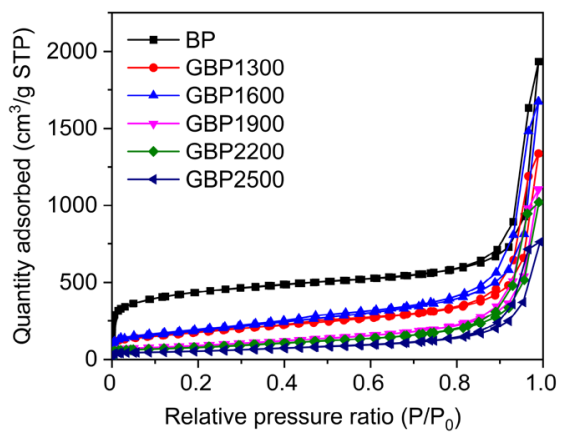

(c)

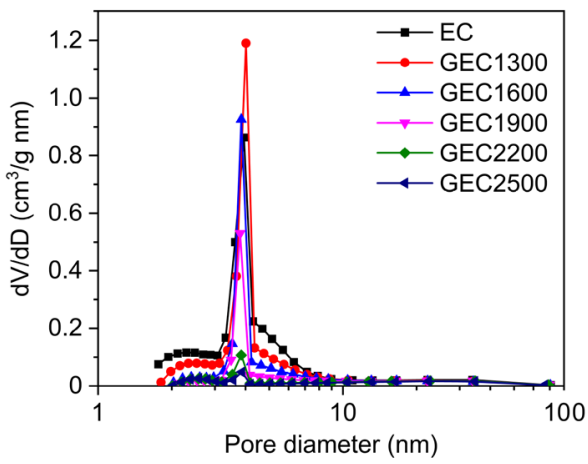

(d)

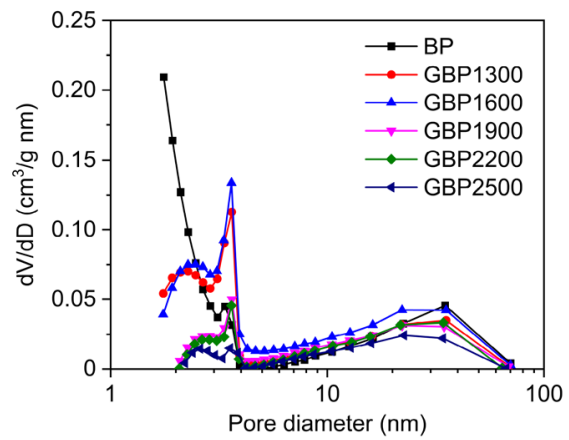

Fig. 2 Isothermal nitrogen adsorption and desorption curves: a EC and GECs, and $\mathbf{b}$ BP and GBPs; pore volume distribution curves: $\mathbf{c}$ EC and GECs, and $\mathbf{d}$ BP and GBPs

high-temperature heat treatment process and forms ordered graphite crystals with low energy levels, thereby increasing the degree of graphitization of carbon.

The isothermal nitrogen adsorption and desorption curves of carbon blacks are shown in Fig. 2a, b, and the calculated BET-specific surface areas are listed in Table 1. 
The BET-specific surface area is negatively related to the heat treatment temperature. The graphitized carbons of GEC2500 and GBP2500 exhibit the lowest specific surface areas. Nonetheless, the specific surface area of GBP2200 $\left(273 \mathrm{~m}^{2} / \mathrm{g}\right)$ is larger than that of XC-72 $\left(228 \mathrm{~m}^{2} / \mathrm{g}\right)$ used in commercial $\mathrm{Pt} / \mathrm{C}$ catalysts. The larger specific surface area can provide more surface to disperse active metals. The pore size distribution of the samples is provided in Fig. 2c, $\mathrm{d}$. The pores can be divided into three types, macropores (diameter $>50 \mathrm{~nm}$ ), mesopores (diameter $=2-50 \mathrm{~nm}$ ) and micropores (diameter $<2 \mathrm{~nm}$ ), based on the pore sizes. The pore size distribution can affect the diffusion of reaction gas and transfer of water products [34].

According to the IUPAC classification, all carbon blacks, EC, GEC, BP, and GBP, exhibit type IV curves. The adsorption process can be divided into the following three stages. First, micropore filling mainly occurs in the low-pressure region with a relative pressure ratio of $0-0.3$. Compared with untreated EC (or BP), the slopes of GEC (or GBP) in this region are smaller, and the total nitrogen adsorption capacity decreases as the temperature increases, indicating that the microporous structure in the carbon black is largely eliminated. Second, a hysteresis loop appears in the medium-pressure region with a relative pressure ratio of $0.3-0.86$, evidencing a mesoporous structure in the sample [35]. Third, in the high-pressure region with a relative pressure ratio of $0.86-0.98$, the slopes of the adsorption and desorption curves increase significantly, revealing that mesopores are the main pore structure of the carbon materials. The hysteresis loop of GEC is smaller than that of GBP under the corresponding treatment temperature, revealing that the mesoporous structure is less abundant in GEC. The pore size distributions of the samples are concentrated in the range of mesopores with a size of approximately $3-4 \mathrm{~nm}$, as exhibited in Fig. 2c, d, revealing that a large number of micropores in amorphous carbon are eliminated during graphitization process. GBP1300 and GBP1600 exhibit similar pore structures, and GBP1900 and GBP2200 share similar pore structures.

\subsection{Electrochemical Stability of the Prepared Carbon Blacks}

Carbon materials, including EC, GEC1300, GEC1600, GEC1900, BP, GBP1300, GBP1600, GBP1900, and GBP2200, have higher specific surface area than that of $\mathrm{XC}-72$ to meet the requirements of ideal carbon support. Then electrochemical tests are performed according to the process provided in Sect. 2.5. The CV curves of the samples are displayed in Fig. 3. In the initial CV cycle of each sample, the anodic peak potential appears at $0.6 \mathrm{~V}$, and the cathodic peak potential appears at $0.55 \mathrm{~V}$. These peaks are related to the electron transfer of the $\mathrm{QH}$ transition on the
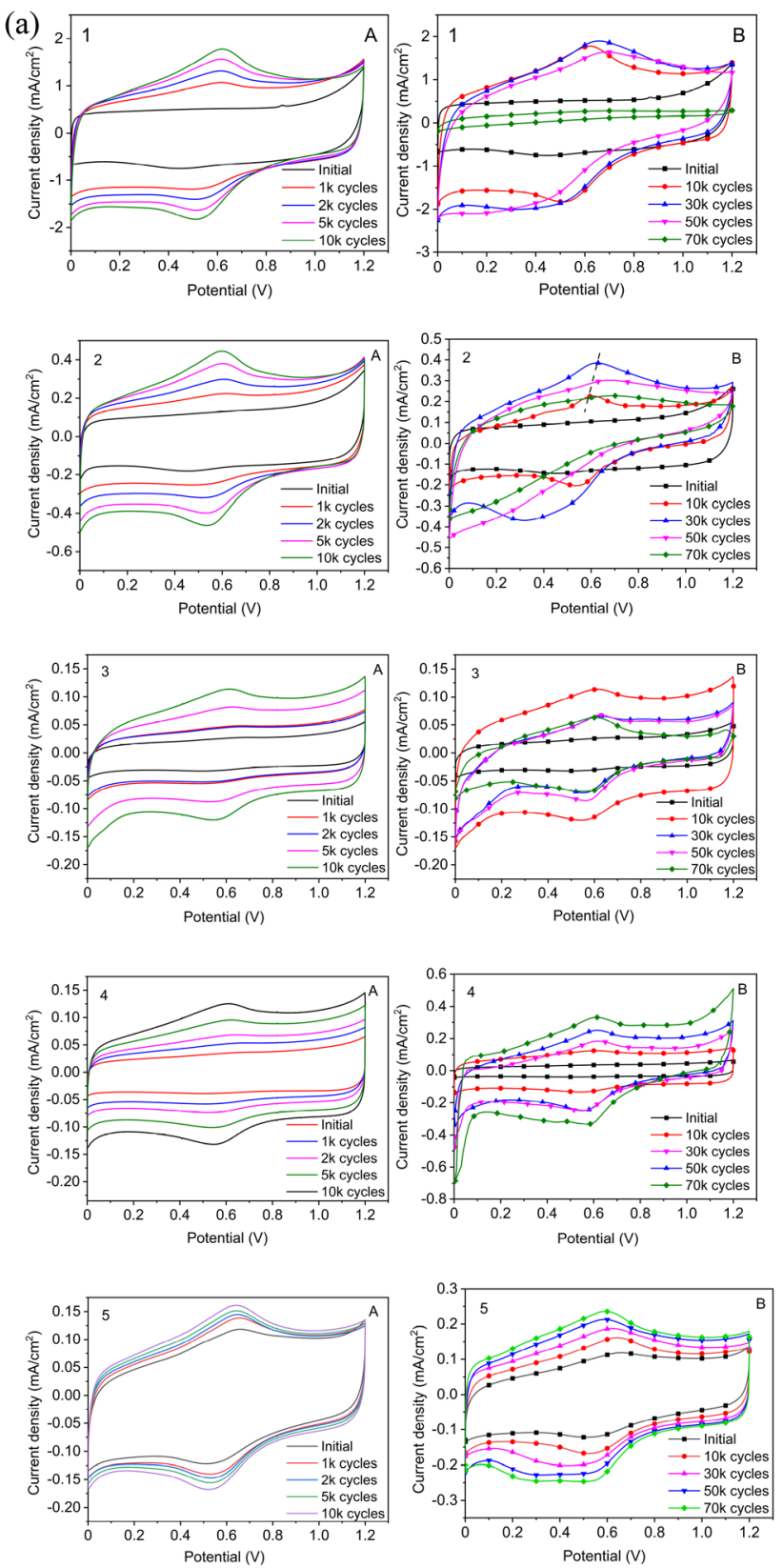

(b)
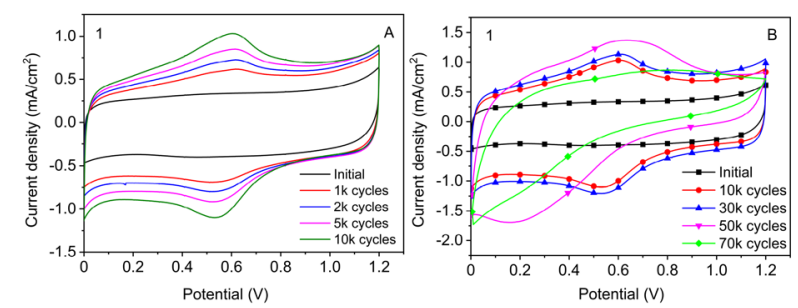

Fig. $3 \mathrm{CV}$ curves of the carbon blacks during AST cycling: a 1-BP, 2-GBP1300, 3-GBP1600, 4-GBP1900, 5-GBP2200; b 1-EC, 2-GEC1300, 3-GEC1600, 4-GEC1900; and c XC-72. Note: 1-70 k cycles $(\mathrm{k}=1000)$ 

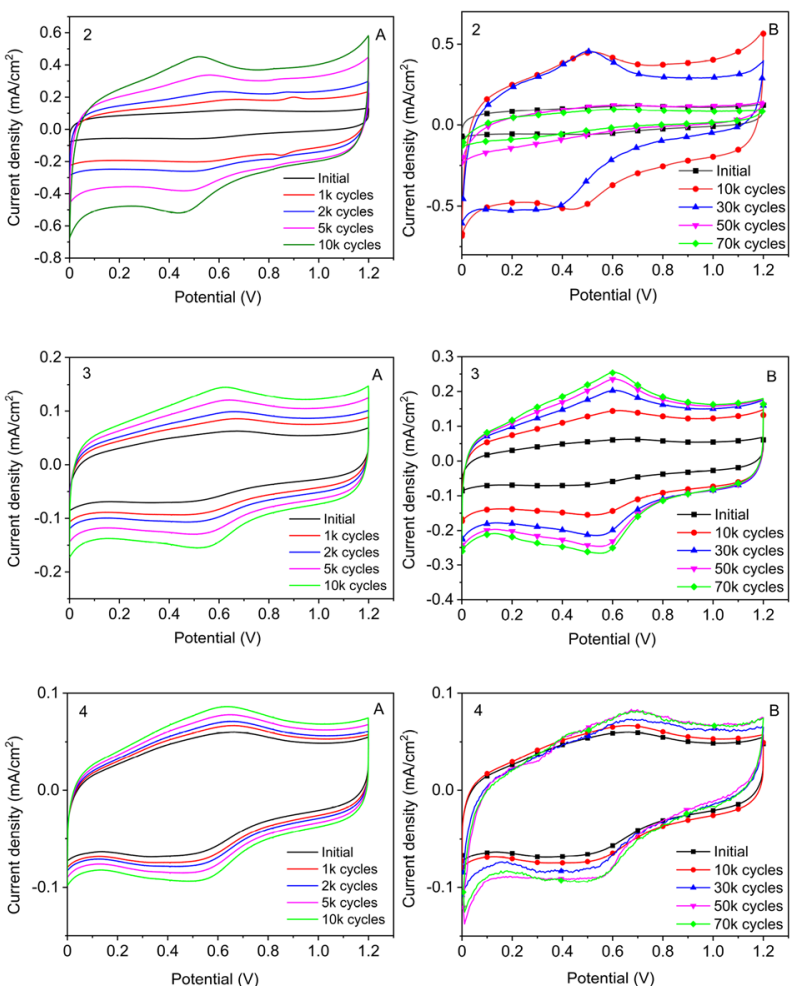

(c)
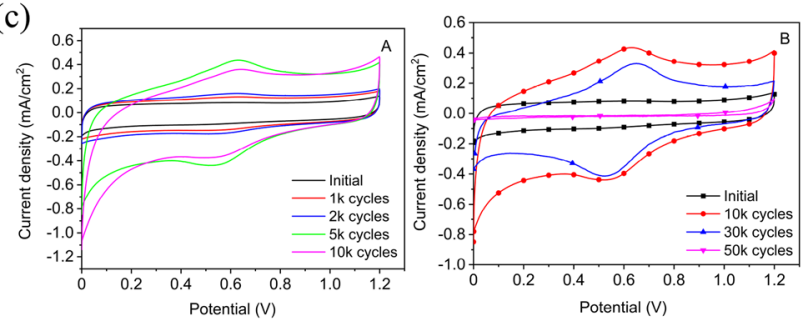

Fig. 3 (continued)

surface. The peak potential is related to the concentration of $\mathrm{QH}$ groups on the carbon surface and the number of adjacent aromatic rings [36, 37]. The oxidation process during cycling can be divided into two stages. During the initial stage, the anodic and cathodic peak currents increase as the number of cycles increases, while the peak potential remains the same. During the second stage, the anodic and cathodic peak potentials shift positively and negatively, respectively, and then, the peaks disappear. During AST cycling, oxidation of the sample mainly results in an increase in the number of $\mathrm{QH}$ groups and the disappearance of contacts between the particles. At the beginning of the carbon oxidation, an increasing quantity of $\mathrm{QH}$ groups is primarily observed, while the amount of grain contacts is practically unchanged. In the 2-stage degradation, the shift of the anodic and cathodic peaks is solely due to the increase in the resistance of the sample, indicating that the connection between the carbon particles begins to break. The porous structure of the carbon is destroyed by oxidation [26]. Generally, amorphous carbon and defective graphite crystals are more prone to corrode and dissolve than the graphitized areas in the oxidation process [38].

As exhibited in Fig. 3, the carbon blacks of XC-72, BP, GBP1300, GBP1600, EC, GEC1300, and GEC1600 subjected to the above process first exhibit a constant peak potential, which then shifts and finally disappears. With the same number of cycles during the AST, GBP1900, GBP2200, and GEC1900 remain in the first stage, that is, the peak current continues to increase with an unchanged $\mathrm{QH}$ peak potential. Thus, the anti-corrosion ability of the prepared carbon blacks is significantly improved when a higher graphitization temperature is employed. Both GEC and GBP exhibit excellent electrochemical stability. Notably, GBP2200 delivers the best stability, as the oxidation remains in the first stage after 70,000 AST cycles.

Notably, GEC possesses a higher degree of graphitization and a smaller specific surface area than GBP, resulting in a decreased loading of Pt. In addition, GEC provides a less mesoporous structure, which is unfavorable for mass transfer. In summary, GBP is more advantageous as carbon support for PEMFCs. Therefore, BP carbon blacks are employed as supports to synthesize Pt catalysts.

\subsection{Performance of the Prepared Catalysts}

Using the formic acid reduction method provided in Sect. 2.5, the selected carbon blacks of BP, GBP1300, GBP1600, GBP1900, GBP2200, and GBP2500 are used as supports to obtain Pt-based catalysts, labeled Pt/BP, Pt/ GBP1300, Pt/GBP1600, Pt/GBP1900, Pt/GBP2200, and Pt/ GBP2500, respectively. The corresponding Pt loadings calculated from the ICP-MS analysis are $40.7 \mathrm{wt} . \%, 39.8 \mathrm{wt} . \%$, 38.4 wt. $\%, 37.8$ wt. $\%, 37.2$ wt. $\%$, and 35.9 wt. $\%$, respectively. This result indicates that graphitized carbon blacks are unfavorable for loading Pt. The higher the degree of graphitization is, the fewer active sites are there on the carbon surface for Pt nucleation, thereby resulting in a decrease in Pt loading.

Figure 4 displays the XRD patterns of the catalysts. All the prepared samples exhibit the typical diffraction peaks of $\mathrm{Pt}$ with a face-centered cubic structure. The assignment of the respective crystal plane is recorded in the diagram. Based on the Scherrer equation, the sizes of $\mathrm{Pt}$ in $\mathrm{Pt} / \mathrm{BP}, \mathrm{Pt} /$ GBP1300, Pt/GBP1600, Pt/GBP1900, Pt/GBP2200, and Pt/ GBP2500 are calculated to be 3.06, 1.97, 2.41, 2.60, 2.39, and $4.06 \mathrm{~nm}$, respectively. The graphite-related peak at $2 \theta=26.5^{\circ}$ is observed for Pt/GBP1900, Pt/GBP2200, and $\mathrm{Pt} / \mathrm{GBP} 2500$, while it is barely observed for the other catalysts because treatment at higher temperatures leads to better graphitization. A stable graphite structure can be obtained at 


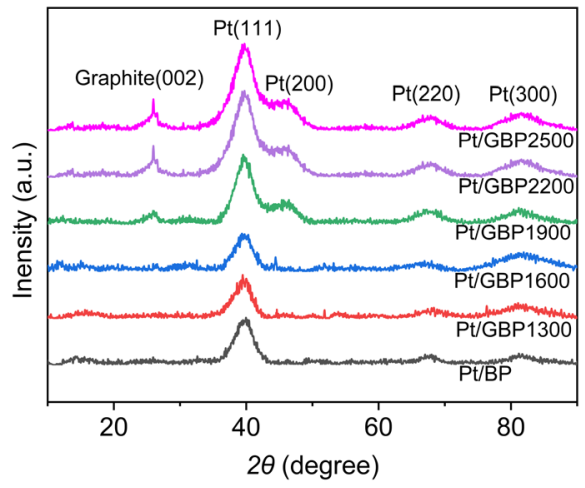

Fig. 4 XRD patterns of the prepared electrocatalysts

a treatment temperature above $1900{ }^{\circ} \mathrm{C}$. Thus, GBP2500 has the most ideal orderly layered graphitization structure but has the fewest available nucleation sites for Pt attachment, causing Pt ion loss during synthesis (the lowest loading of 35.9\%) and Pt particle agglomeration (the largest particle size of $4.06 \mathrm{~nm}$ ). The similar properties of GBP1900 and GBP2200 provided in Sect. 3.1 result in the similar characterization of Pt/GBP1900 and Pt/GBP2200.

Figure 5 exhibits TEM images of various carbon blacksupported catalysts, providing the initial and post-AST morphologies. The Pt particles in the initial Pt/BP, Pt/ GBP1300, and Pt/GBP1600 samples exhibit better dispersion than those in Pt/GBP1900, Pt/GBP2200, and Pt/ GBP2500, which is reasonable because their larger BET specific surface area can provide more anchor points for $\mathrm{Pt}$ atom deposition; thus, better dispersion of Pt nanoparticles is obtained. These results agree with the BET analysis. The layered ordered graphitized structure of the carbon support can be clearly observed in Pt/GBP1600, Pt/GBP1900, Pt/ GBP2200, and Pt/GBP2500, while it is barely observed in $\mathrm{Pt} / \mathrm{BP}$ and Pt/GBP1300. With an increasing heat treatment temperature for carbon black graphitization, more graphite structures are generated. Notably, the layered structure of Pt/GBP1600 disappears after undergoing the AST, while Pt/GBP1900, Pt/GBP2200, and Pt/GBP2500 retain part of their graphite structure. Additionally, agglomeration of $\mathrm{Pt}$ particles is observed for all catalysts after the AST.

\subsection{RDE Performance of the Prepared Catalysts}

Figure $6 \mathrm{a}, \mathrm{b}$ shows the initial CV and LSV curves of all prepared catalysts, respectively. The ECSA and MA of each sample during AST cycling are computed on the basis of the formulas provided in Sect. 2.5. The calculated values in the initial state and final state (after 10,000 AST cycles) are listed in Table 2. The corresponding ECSA and MA decay rates of each catalyst during AST cycling are shown in Fig. 6c, d, respectively. Pt/GBP1300 provides the best
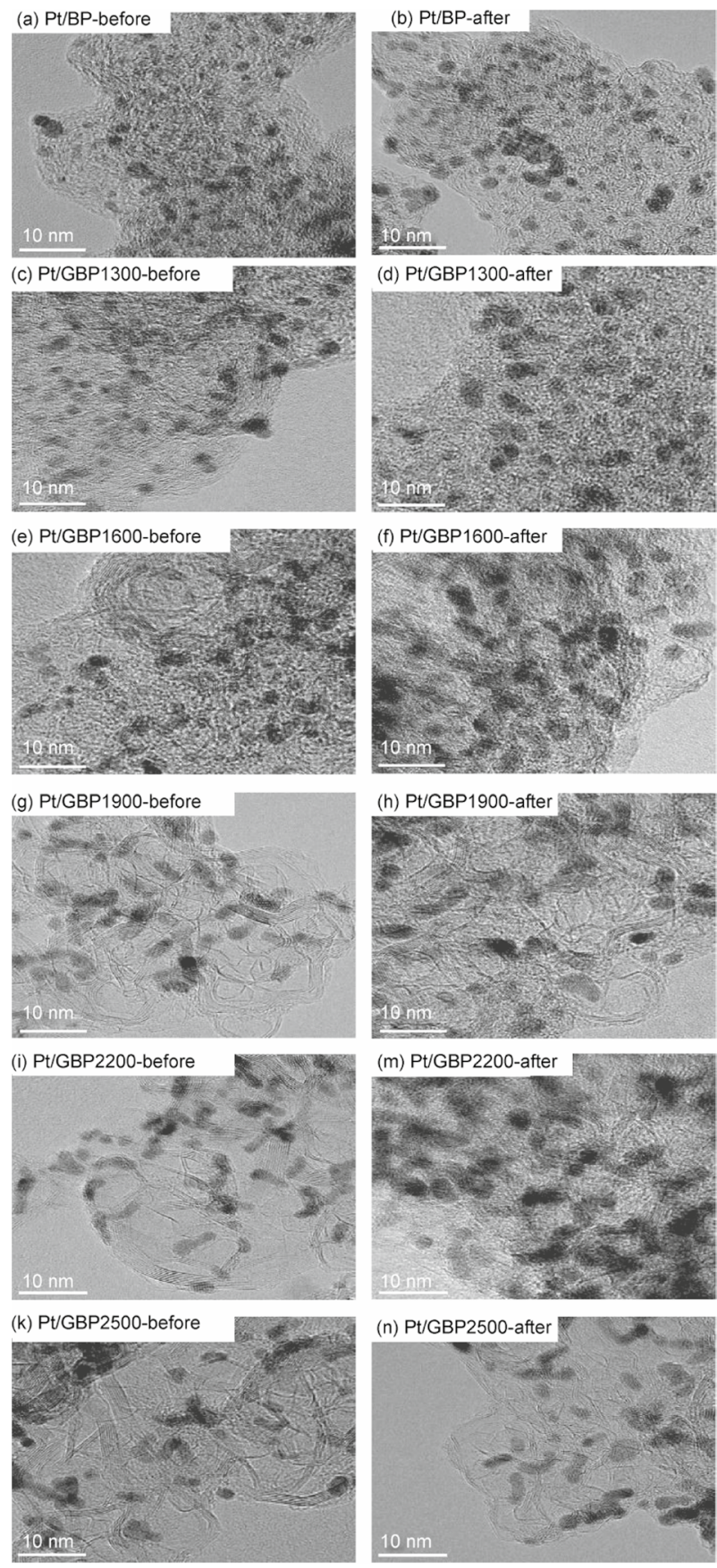

Fig. 5 TEM images: a, b Pt/BP; c, d Pt/GBP1300; e, f Pt/GBP1600; g, h Pt/GBP1900; i, m Pt/GBP2200; and k, n Pt/GBP2500. Note a, c, $\mathbf{e}, \mathbf{g}, \mathbf{i}, \mathbf{k}$ correspond to before the AST (initial state), and $\mathbf{b}, \mathbf{d}, \mathbf{f}, \mathbf{h}, \mathbf{m}$, n correspond to after the AST (final state)

initial performance. After 10,000 AST cycles, Pt/BP suffers the most serious degradation. The attenuation rates of the ECSA and MA reach $55.06 \%$ (from 82.37 to $37.02 \mathrm{~m}^{2} / \mathrm{g}_{\mathrm{Pt}}$ ) and $82.01 \%$ (from 108.60 to $19.23 \mathrm{~mA} / \mathrm{mg}_{\mathrm{Pt}}$ ), respectively. The MA attenuation rate of Pt/GBP2200 is $25.01 \%$ (from 85.11 to $47.87 \mathrm{~mA} / \mathrm{mg}_{\mathrm{Pt}}$ ). 
(a)

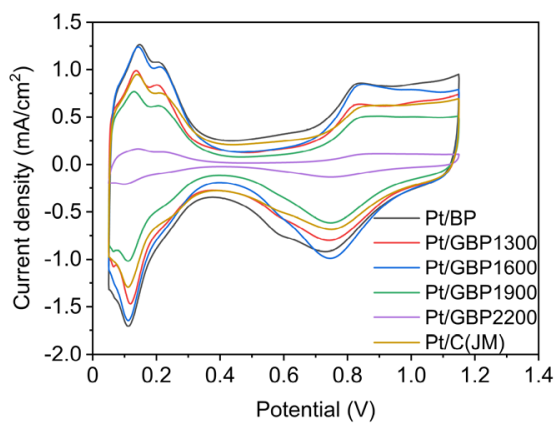

(b)

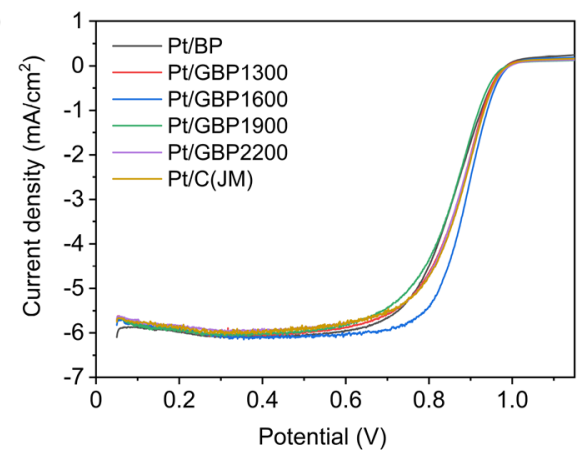

(c)

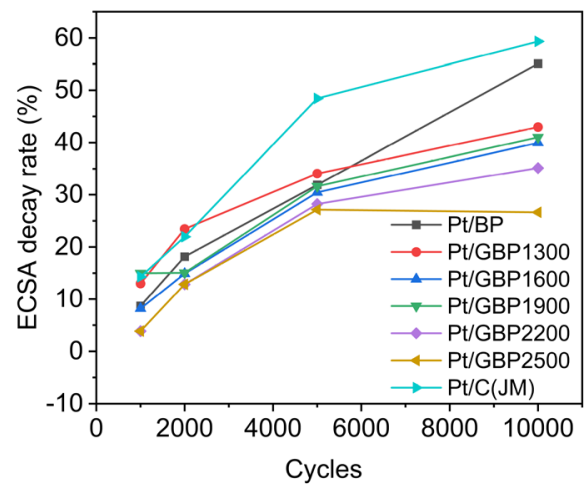

(d)

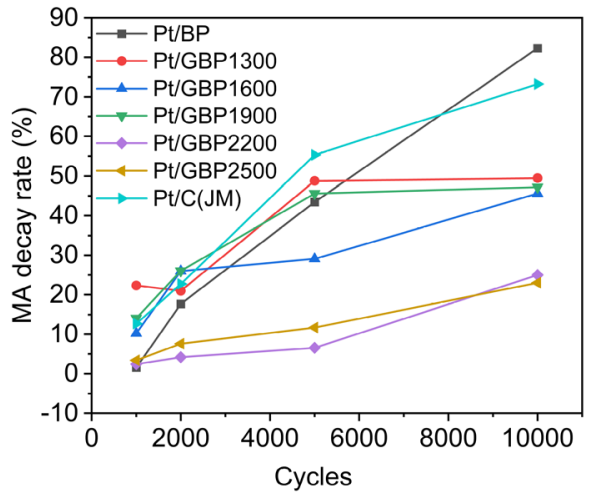

Fig. 6 Performance of the prepared catalysts in RDE: a CV curves of each catalyst in their initial state; $\mathbf{b}$ LSV curves of each catalyst in their initial state; c ECSA decay rate of each sample during AST cycling; and d MA decay rate of each sample during AST cycling

Carbon black substrates can be severely corroded in an acidic $\mathrm{HClO}_{4}$ solution and under high potential conditions, thereby inducing performance degradation of the corresponding catalyst. The graphite sheet structure in the GBP graphitized carbon exhibits better anti-corrosion ability and enhanced interaction between $\pi$ electrons in the graphite structure and Pt particles. Therefore, the durability of the GBP-supported catalysts is better than that of $\mathrm{Pt} / \mathrm{BP}$ and commercial Pt/C-supported ones. This result agrees with the analysis of the initial and post-AST TEM images, which confirms that Pt /GBP1900, Pt/GBP2200 and Pt/GBP2500 have better durability in the AST. The ordered graphite structure with fewer surface defects inhibits deposition and adhesion of Pt nanoparticles, leading to a worse dispersion of Pt particles. Nevertheless, the graphite structure provides a stronger anti-corrosion ability.

\subsection{MEA Performance of the Prepared Catalysts}

Pt/GBP2200 is selected to prepare an MEA because of its optimum initial and durable overall performance at the RDE level, and commercial $\mathrm{Pt} / \mathrm{C}(\mathrm{JM})$ is selected as its counterpart. Figure 7 a shows the polarization curve and power density curve of MEA-JM and MEA-Pt/GBP2200 before and after the AST. The initial performance of MEA-Pt/GBP2200 is slightly worse than that of MEA-JM. The maximum power density of MEA-Pt/GBP2200 is $759.68 \mathrm{~mW} / \mathrm{cm}^{2}$, which is $73.8 \mathrm{~mW} / \mathrm{cm}^{2}$ lower than that of MEA-JM. Nonetheless, the performance degradation of MEA-Pt/GBP2200 is much slower than that of MEA-JM after 5000 AST cycles. The final maximum power density of MEA-Pt/GBP2200 is $525.68 \mathrm{~mW} / \mathrm{cm}^{2}$, which is $305.52 \mathrm{~mW} / \mathrm{cm}^{2}$ higher than that of MEA-JM. The enhanced durability of MEA-Pt/GBP2200 might be attributed to the stronger electrochemical stability and anticorrosion ability of its carbon support. The carbon support of MEA-JM is corroded and falls off during the high-potential AST, which causes the Pt loaded on the support to migrate and agglomerate and results in a significant decrease in the fuel cell performance. The decay rate of the maximum power density of MEA-Pt/GBP2200 is $30.80 \%$, which is much lower than the value of $73.59 \%$ for MEA-JM. After 5000 AST cycles, the voltage drop at $800 \mathrm{~mA} / \mathrm{cm}^{2}$ of MEA-Pt/GBP2200 is $0.104 \mathrm{~V}$ (from 0.637 drop to $0.533 \mathrm{~V}$ ), while the value of MEA-Pt/C is $0.398 \mathrm{~V}$ (from 0.662 drop to $0.264 \mathrm{~V}$ ), indicating that the MEA-JM has suffered severe performance degradation during AST cycling.

The Nyquist plots obtained from the EIS tests of the two MEAs at $800 \mathrm{~mA} / \mathrm{cm}^{2}$ during the AST are displayed in Fig. 7b, c. Generally, the first intersection with the horizontal axis is the high-frequency resistance (HFR), which represents the ohmic polarization loss of PEMFCs. The first arc reflects the charge transfer impedance at high frequency. The second arc at the low-frequency represents the mass transfer impedance, which is dominated by oxygen diffusion [39]. During the AST, the arc diameter first increases and then decreases, which is related to 
Table 2 Parameters of the prepared catalysts in the RDE tests

\begin{tabular}{lllll}
\hline Catalysts & \multicolumn{3}{l}{ Parameter } & \\
\cline { 2 - 5 } & $\begin{array}{l}\text { ECSA of initial state } \\
\left(\mathrm{m}^{2} / \mathrm{g}_{\mathrm{Pt}}\right)\end{array}$ & $\begin{array}{l}\text { ECSA of final state } \\
\left(\mathrm{m}^{2} / \mathrm{g}_{\mathrm{Pt}}\right)\end{array}$ & $\begin{array}{l}\text { MA of initial state } \\
\left(\mathrm{m}^{2} / \mathrm{g}_{\mathrm{Pt}}\right)\end{array}$ & $\begin{array}{l}\text { MA of final } \\
\text { state }(\mathrm{mA} / \\
\left.\mathrm{mg}_{\mathrm{Pt}}\right)\end{array}$ \\
\hline $\mathrm{Pt} / \mathrm{BP}$ & 82.37 & 37.02 & 108.60 & 19.23 \\
$\mathrm{Pt} / \mathrm{GBP} 1300$ & 97.08 & 55.36 & 103.15 & 49.52 \\
$\mathrm{Pt} / \mathrm{GBP} 1600$ & 68.01 & 40.83 & 98.51 & 44.63 \\
$\mathrm{Pt} / \mathrm{GBP} 1900$ & 63.98 & 37.74 & 93.28 & 32.47 \\
$\mathrm{Pt} / \mathrm{GBP} 2200$ & 41.35 & 26.82 & 85.11 & 47.87 \\
$\mathrm{Pt} / \mathrm{GBP} 2500$ & 20.67 & 15.17 & 51.17 & 32.14 \\
$\mathrm{Pt} / \mathrm{C}(\mathrm{JM})$ & 60.45 & 24.58 & 86.83 & 23.31 \\
\hline
\end{tabular}

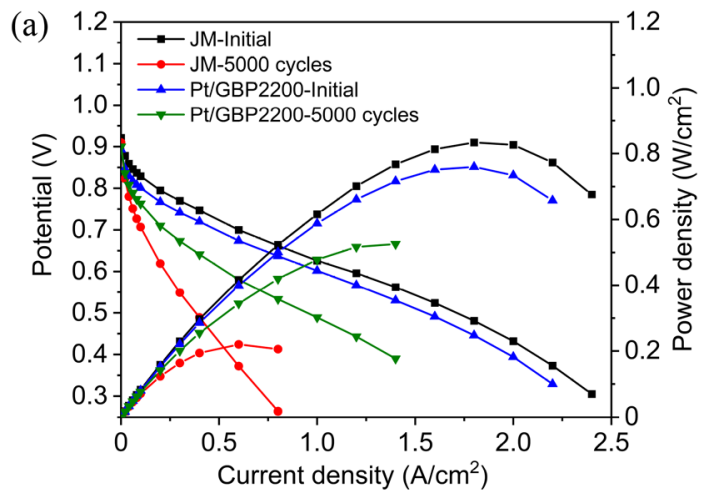

(b)

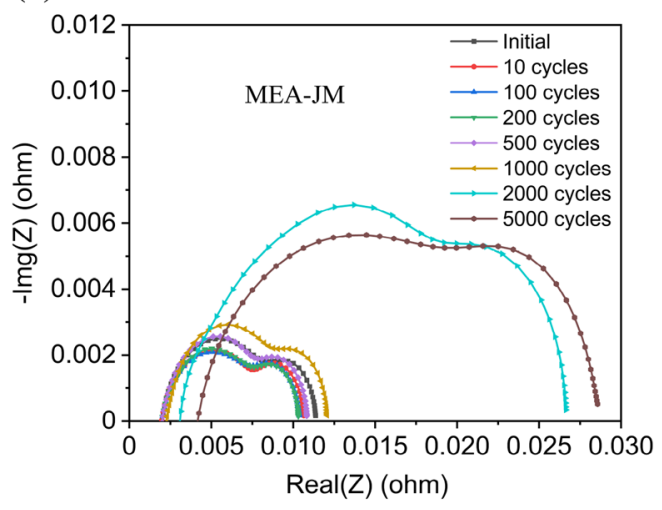

(c)

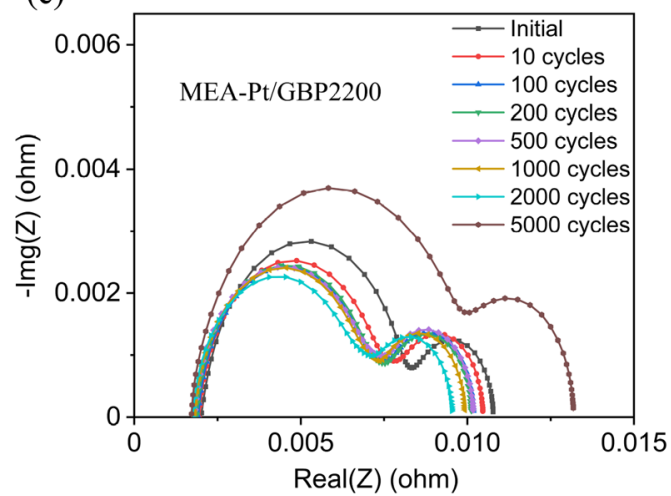

Fig. 7 Performance of the prepared MEAs: a Comparison of the polarization curves and power density curves of the MEAs; EIS at $800 \mathrm{~mA} / \mathrm{cm}^{2}$ during the AST of $\mathbf{b}$ commercial MEA-JM, and $\mathbf{c}$ MEA$\mathrm{Pt} / \mathrm{GBP} 2200$ activation during the early stage and attenuation during the later stage. This behavior agrees with the test results of the polarization curves. In the AST process of MEA-Pt/C, the HFR is also clearly observed to begin to increase after 1000 cycles, along with increases in the charge transfer and mass transfer impedances. By contrast, the HFR of the MEA-Pt/GBP2200 remains almost unchanged, which can be attributed to the stability of the graphitized carbon support. After a certain AST cycle, the charge transfer resistance sharply increases, which is related to carbon support oxidation and Pt particle agglomeration [14]. The charge transfer resistance of MEA-Pt/GBP2200 increases significantly from 2000 to 5000 cycles. By contrast, the charge transfer resistance of MEA-JM begins to increase after only 200 cycles during the AST. The graphitization effect significantly delays the critical point at which the charge transfer resistance begins to increase. This phenomenon indicates that chemically durable GBP2200 effectively prevents physicochemical degradation of the carbon support.

Figure $8 \mathrm{a}, \mathrm{b}$ exhibits the in situ $\mathrm{CV}$ curves of the single cells before and after the high-potential AST of MEA-JM and MEA-Pt/GBP2200, respectively. The CV curves show typical $\mathrm{H}$ adsorption/desorption peaks. ECSA for each MEA is obtained with the calculation method provided in Sect. 2.5. Commercial MEA-JM suffers severe degradation during the high-potential AST, although it delivers a larger initial ECSA. The ECSA decreases from 51.16 to $10.68 \mathrm{~m}^{2} /$ $\mathrm{g}_{\mathrm{Pt}}$, and the decay rate is $79.12 \%$. By contrast, the ECSA decay rate of MEA-Pt/GBP2200 is $46.47 \%$ (from 28.12 to $15.05 \mathrm{~m}^{2} / \mathrm{g}_{\mathrm{Pt}}$ ), which is merely half that of MEA-Pt/C. This improvement in the anti-corrosion capacity of the carbon support might contribute to decreasing the ECSA loss and increasing the MEA durability.

In Fig. 8b, the quinone redox peak at $\sim 0.6 \mathrm{~V}$ after 5000 cycles for Pt/GBP-2200 is associated with the carbon support corrosion during the AST cycling [21], while in Fig. 8a, the quinone redox peak at $\sim 0.6 \mathrm{~V}$ appears in the initial $\mathrm{CV}$ cycle of MEA-JM and disappears after 5000 cycles, indicating that the carbon support of Pt/C-JM has undergone the 
(a)

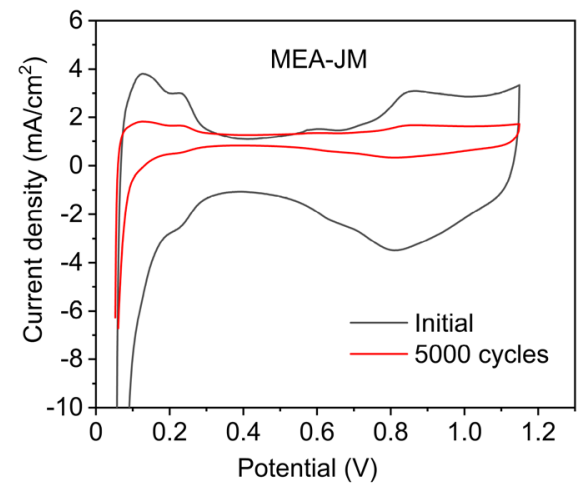

(b)

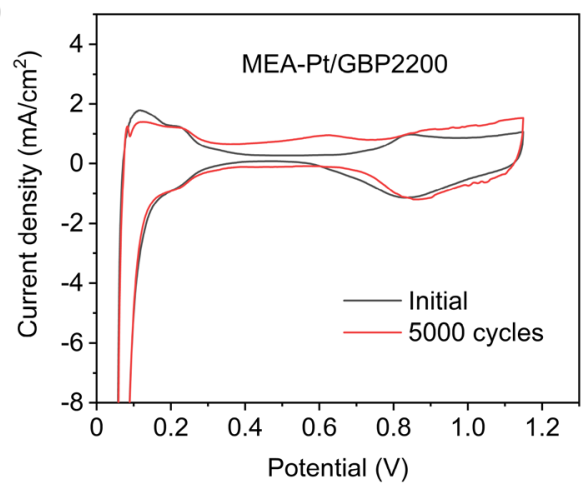

Fig. 8 CV curves of the MEAs during the AST: a commercial MEAJM, and b MEA-Pt/GBP2200

overall quinone redox stages. Ordinary carbon black supports are more susceptible to corrosion under high potential, decaying the overall performance of single cells. Thus, these results show that the durability of MEA-Pt/GBP2200 is much better than that of commercial MEA-JM.

\section{Conclusions}

Two types of carbon black supports have been modified under a sequence of graphitization temperatures, and their anticorrosion ability has been evaluated by an efficient AST method for selecting carbon blacks as supports. The Pt catalyst supported on optimally graphitized carbon blacks achieves enhanced durability for the ORR at both the RDE and MEA levels.

As the heat treatment temperature rises, the ordered graphite structure in the obtained carbon increases, accompanied by an improvement in the antioxidation capacity during the AST. The shift in the QH peak position of GBP carbon blacks occurs much later than that of their GEC counterparts during the AST, indicating that GBP possesses a stronger anti-corrosion capability. In addition, GBP provides a more porous structure and a larger BET-specific surface area than the corresponding GEC. Thus, GBP shows better qualities as catalyst support for the ORR.
The durability of the Pt/GBP2200 catalyst is 2 times higher than that of the commercial $\mathrm{Pt} / \mathrm{C}$ catalyst with no loss of initial performance during the RDE tests. Moreover, during the MEA test, the decay rate of its maximum power density is less than half of that of the commercial Pt/C catalyst. This paper provides an efficient strategy to select carbon substrates as ideal supports for vehicle PEMFCs.

Acknowledgments This work is supported by the Program of Ministry of Science \& Technology of China. In detail, the title of the subject is the development of sealing and batch assembly process technology equipment for fuel cell stacks (No. 2018YFB1502505).

\section{Declarations}

Conflict of interest On behalf of all the authors, the corresponding author states that there is no conflict of interest.

Open Access This article is licensed under a Creative Commons Attribution 4.0 International License, which permits use, sharing, adaptation, distribution and reproduction in any medium or format, as long as you give appropriate credit to the original author(s) and the source, provide a link to the Creative Commons licence, and indicate if changes were made. The images or other third party material in this article are included in the article's Creative Commons licence, unless indicated otherwise in a credit line to the material. If material is not included in the article's Creative Commons licence and your intended use is not permitted by statutory regulation or exceeds the permitted use, you will need to obtain permission directly from the copyright holder. To view a copy of this licence, visit http://creativecommons.org/licenses/by/4.0/.

\section{References}

1. Staffell, I., Scamman, D., Abad, A.V., et al.: The role of hydrogen and fuel cells in the global energy system. Energy Environ. Sci. 12(2), 463-491 (2019)

2. Kurtz, J., Sprik, S., Bradley, T.H.: Review of transportation hydrogen infrastructure performance and reliability. Int. J. Hydrogol. Energy 44(23), 12010-12023 (2019)

3. Rocco, M.V., Casalegno, A., Colombo, E.: Modelling road transport technologies in future scenarios: theoretical comparison and application of well-to-wheels and input-output analyses. Appl. Energy 232, 583-597 (2018)

4. U.S. DRIVE: Fuel Cell Technical Team Roadmap. https://www. energy.gov/sites/default/files/2017/11/f46/FCTT_Roadmap_Nov_ 2017_FINAL.pdf. Accessed November 2017

5. Gittleman, C.S., Kongkanand, A., Masten, D., Gu, W.B.: Materials research and development focus areas for low cost automotive proton-exchange membrane fuel cells. Curr. Opin. Electrochem. 18, 81-89 (2019)

6. Wang, X.X., Swihart, M.T., Wu, G.: Achievements, challenges and perspectives on cathode catalysts in proton exchange membrane fuel cells for transportation. Nat. Catal. 2(7), 578-589 (2019)

7. Shao, M.H., Chang, Q.W., Dodelet, J.P., Chenitz, R.: Recent advances in electrocatalysts for oxygen reduction reaction. Chem. Rev. 116(6), 3594-3657 (2016)

8. Thompson, S.T., Papageorgopoulos, D.: Platinum group metalfree catalysts boost cost competitiveness of fuel cell vehicles. Nat. Catal. 2(7), 558-561 (2019) 
9. He, Y.H., Liu, S.W., Priest, C., Shi, Q.R., Wu, G.: Atomically dispersed metal-nitrogen-carbon catalysts for fuel cells: advances in catalyst design, electrode performance, and durability improvement. Chem. Soc. Rev. 49(11), 3484-3524 (2020)

10. Singh, H., Zhuang, S.Q., Ingis, B., Nunna, B.B., Lee, E.S.: Carbon-based catalysts for oxygen reduction reaction: a review on degradation mechanisms. Carbon 151, 160-174 (2019)

11. Zhu, F.J., Luo, L.X., Wu, A.M., et al.: Improving the high-currentdensity performance of PEMFC through much enhanced utilization of platinum electrocatalysts on carbon. ACS Appl. Mater. Interfaces 12(23), 26076-26083 (2020)

12. Sui, S., Wang, X.Y., Zhou, X.T., Su, Y.H., Riffatc, S., Liu, C.J.: A comprehensive review of Pt electrocatalysts for the oxygen reduction reaction: nanostructure, activity, mechanism and carbon support in PEM fuel cells. J. Mater. Chem. A 5(5), 1808-1825 (2017)

13. Wang, Y.J., Zhao, N.N., Fang, B.Z., Li, H., Bi, X.T.T., Wang, H.J.: Carbon-supported Pt-based alloy electrocatalysts for the oxygen reduction reaction in polymer electrolyte membrane fuel cells: particle size, shape, and composition manipulation and their impact to activity. Chem. Rev. 115(9), 3433-3467 (2015)

14. Lee, S.W., Choi, S.R., Jang, J., Park, G.G., Yu, S.H., Park, J.Y.: Tolerance to carbon corrosion of various carbon structures as catalyst supports for polymer electrolyte membrane fuel cells. J. Mater. Chem. A 7(43), 25056-25065 (2019)

15. Jayabal, S., Saranya, G., Geng, D.S., Lin, L.Y., Meng, X.B.: Insight into the correlation of Pt-support interactions with electrocatalytic activity and durability in fuel cells. J. Mater. Chem. A 8(19), 9420-9446 (2020)

16. Forouzandeh, F., Li, X.A., Banham, D.W., Feng, F.X., Ye, S.Y., Birss, V.: Evaluation of the corrosion resistance of carbons for use as PEM fuel cell cathode supports. J. Electrochem. Soc. 162(12), F1333-F1341 (2015)

17. Park, Y.C., Kakinuma, K., Uchida, M., et al.: Investigation of the corrosion of carbon supports in polymer electrolyte fuel cells using simulated start-up/shutdown cycling. Electrochim. Acta 91, 195-207 (2013)

18. Kim, J.H., Cheon, J.Y., Shin, T.J., Park, J.Y., Joo, S.H.: Effect of surface oxygen functionalization of carbon support on the activity and durability of $\mathrm{Pt} / \mathrm{C}$ catalysts for the oxygen reduction reaction. Carbon 101, 449-457 (2016)

19. Lee, G., Choi, H., Tak, Y.: In situ durability of various carbon supports against carbon corrosion during fuel starvation in a PEM fuel cell cathode. Nanotechnology 30(8), 10 (2019)

20. Schulenburg, H., Schwanitz, B., Linse, N., et al.: 3D imaging of catalyst support corrosion in polymer electrolyte fuel cells. J. Phys. Chem. C 115(29), 14236-14243 (2011)

21. Macauley, N., Papadias, D.D., Fairweather, J., et al.: Carbon corrosion in PEM fuel cells and the development of accelerated stress tests. J. Electrochem. Soc. 165(6), F3148-F3160 (2018)

22. Linse, N., Scherer, G.G., Wokaun, A., Gubler, L.: Quantitative analysis of carbon corrosion during fuel cell start-up and shutdown by anode purging. J. Power Sources 219, 240-248 (2012)

23. Cremers, C., Jurzinsky, T., Meier, J., et al.: DEMS and online mass spectrometry studies of the carbon support corrosion under various polymer electrolyte membrane fuel cell operating conditions. J. Electrochem. Soc. 165, F3307-F3315 (2018)

24. Castanheira, L., Silva, W.O., Lima, F.H.B., Crisci, A., Dubau, L., Maillard, F.: Carbon corrosion in proton-exchange membrane fuel cells: effect of the carbon structure, the degradation protocol, and the gas atmosphere. ACS Catal. 5(4), 2184-2194 (2015)

25. Dubau, L., Castanheira, L., Maillard, F., et al.: A review of PEM fuel cell durability: materials degradation, local heterogeneities of aging and possible mitigation strategies. Wiley Interdiscip. Rev. Energy Environ. 3(6), 540-560 (2014)

26. Gribov, E.N., Maltseva, N.V., Golovin, V.A., Okunev, A.G.: A simple method for estimating the electrochemical stability of the carbon materials. Int. J. Hydrog. Energy 41(40), 18207-18213 (2016)

27. Selvaganesh, S.V., Selvarani, G., Sridhar, P., Pitchumani, S., Shukla, A.K.: Graphitic carbon as durable cathode-catalyst support for PEFCs. Fuel Cells 11(3), 372-384 (2011)

28. Xue, Q., Li, J.K., Yang, Z.Y.: Synergistically improving the activity, antipoisonous ability, and long-term stability of Pt to methanol oxidation through developing favorable graphene-based supports. Langmuir 33(4), 872-880 (2017)

29. Wang, Y.J., Fang, B.Z., Li, H., Bi, X.T.T., Wang, H.J.: Progress in modified carbon support materials for Pt and Pt-alloy cathode catalysts in polymer electrolyte membrane fuel cells. Prog. Mater. Sci. 82, 445-498 (2016)

30. Huang, X.Q., Zhao, Z.P., Chen, Y., et al.: A rational design of carbon-supported dispersive Pt-based octahedra as efficient oxygen reduction reaction catalysts. Energy Environ. Sci. 7(9), 2957-2962 (2014)

31. Osswald, S., Flahaut, E., Gogotsi, Y.: In situ Raman spectroscopy study of oxidation of double- and single-wall carbon nanotubes. Chem. Mat. 18(6), 1525-1533 (2006)

32. Sadezky, A., Muckenhuber, H., Grothe, H., Niessner, R., Poschl, U.: Raman micro spectroscopy of soot and related carbonaceous materials: spectral analysis and structural information. Carbon 43(8), 1731-1742 (2005)

33. Dresselhaus, M.S., Dresselhaus, G., Jorio, A., Souza, A.G., Saito, R.: Raman spectroscopy on isolated single wall carbon nanotubes. Carbon 40(12), 2043-2061 (2002)

34. Chang, H., Joo, S.H., Pak, C.: Synthesis and characterization of mesoporous carbon for fuel cell applications. J. Mater. Chem. 17(30), 3078-3088 (2007)

35. Krishnankutty, N., Vannice, M.A.: Effect of pretreatment on surface-area, porosity, and adsorption properties of a carbon-black. Chem. Mat. 7(4), 754-763 (1995)

36. Shi, H.: Activated carbons and double layer capacitance. Electrochim. Acta 41(10), 1633-1639 (1996)

37. Tarasevich, M.R., Bogdanovskaya, V.A., Zagudaeva, N.M.: Redox reactions of quinones on carbon materials. J. Electroanal. Chem. 223(1-2), 161-169 (1987)

38. Castanheira, L., Dubau, L., Mermoux, M., et al.: Carbon corrosion in proton-exchange membrane fuel cells: from model experiments to real-life operation in membrane electrode assemblies. ACS Catal. 4(7), 2258-2267 (2014)

39. Xue, Q., Yang, D.J., Wang, J., Li, B., Ming, P.W., Zhang, C.M.: Enhanced mass transfer and proton conduction of cathode catalyst layer for proton exchange membrane fuel cell through filling polyhedral oligomeric silsesquioxane. J. Power Sources (2021). https://doi.org/10.1016/j.jpowsour.2020.229413 